\title{
The relationship between the implementation of voluntary Five-Star occupational health and safety management system and the incidence of fatal and permanently disabling injury
}

\section{Hedlund, Frank Huess}

\section{Published in:}

Safety Science

Link to article, DOI:

10.1016/j.ssci.2013.10.025

Publication date:

2014

Document Version

Early version, also known as pre-print

Link back to DTU Orbit

Citation (APA):

Hedlund, F. H. (2014). The relationship between the implementation of voluntary Five-Star occupational health and safety management system and the incidence of fatal and permanently disabling injury. Safety Science, 63, 94-103. https://doi.org/10.1016/j.ssci.2013.10.025

\section{General rights}

Copyright and moral rights for the publications made accessible in the public portal are retained by the authors and/or other copyright owners and it is a condition of accessing publications that users recognise and abide by the legal requirements associated with these rights.

- Users may download and print one copy of any publication from the public portal for the purpose of private study or research.

- You may not further distribute the material or use it for any profit-making activity or commercial gain

- You may freely distribute the URL identifying the publication in the public portal 
The relationship between the implementation of voluntary Five-Star occupational health and safety management system and the incidence of fatal and permanently disabling injury 
Frank Huess HEDLUND, Technical University of Denmark, (DTU/Compute) DK-2800 Kongens Lyngby, Denmark. E-mail fhuhe@,dtu.dk Tel: +45 45252525

COWI; Parallelvej 2, DK-2800 Kongens Lyngby, Denmark ${ }^{\mathrm{a}}$. E-mail: fhhe@cowi.dk Tel: +4556400000

${ }^{a}$ corresponding address

\begin{abstract}
This paper examines two properties of the South African NOSA 5-Star System, a voluntary occupational health and safety (OHS) management system. The first property is the association between system implementation and final OHS outcomes measured as incidence rates of fatal and permanently disabling injury. The second is the association between the Star audit rating and rates of serious occupational injury.
\end{abstract}

Although there are many uncertainties involved the paper argues that companies committed to the NOSA system experienced fewer fatal and permanently disabling injuries than the general manufacturing sector. The paper also examines an inverse correlation between the Star rating and the injury incidence rate. It is concluded that the Star rating is a sound although imperfect predictor of injury rates. The fact that auditing is an entirely voluntary activity likely distorts the Star rating to some extent. It is speculated that some (unsafe) companies may abandon or pause auditing if they experience too many injuries. There is also some evidence to suggest that companies with poor safety attitudes are able to successfully deceive auditors.

The paper suggests that voluntary OHS audit systems are embedded in structural problems that set limits to what they can reasonably be expected to accomplish. The fundamental issues are about naivety and the intrinsic viability of self-regulation. In a broader view however, the adoption of such systems might well be endorsed by policymakers because of their positive impact on OHS. It is clear though, that such systems cannot substitute authority enforcement activities.

Keywords: voluntary occupational health and safety (OHS) management system, audit score, effectiveness, final OHS outcomes 
Research highlights

- The NOSA 5-Star System is a voluntary occupational safety management system

- System implementation is measured with a Star-rating

- NOSA companies have a lower incidence of serious occupational injury

- There is inverse correlation between the Star rating and the incidence rate of serious injury

- The Star rating is a sound although imperfect predictor of injury rates 


\section{Table of Contents}

1 Introduction 5

$\begin{array}{lll}1.1 & \text { Background } & 5\end{array}$

1.2 History of the National Occupational Safety

1.3 The NOSA 5-Star System 6

1.4 Critique of 5-Star systems 9

1.5 A critical review of the critique 10

$\begin{array}{lll}1.6 & \text { Justification for this study } & 10\end{array}$

2 Method 12

2.1 Methodological considerations 12

$\begin{array}{lll}2.2 & \text { Data collection procedure } & 13\end{array}$

3 Results $\quad 15$

$\begin{array}{lll}3.1 & \text { Response rate } & 15\end{array}$

3.2 Population properties 15

$\begin{array}{lll}3.3 & 18\end{array}$

$\begin{array}{lll}3.4 & \text { Reference group } & 19\end{array}$

Accident experience of questionnaire sample
companies

4 Discussion $\quad 23$

4.1 Potential errors in survey sample data 23

$4.2 \quad$ No control group $\quad 24$

4.3 Accident rates for reference group 24

Distortions due to the voluntary nature of NOSA
auditing

Implications for voluntary OHS management
systems 
The relationship between the implementation of voluntary Five-Star occupational health and safety management system and the incidence of fatal and permanently disabling injury

$5 \quad$ Conclusion

$6 \quad$ Acknowledgements 


\section{Introduction}

\section{$1.1 \quad$ Background}

For decades, systematic occupational health and safety (OHS) management has been the main international strategy to improve health and safety at work. Two categories exist. 1) Mandatory regulations of OHS management are public politics codified into law and compliance is supervised by labour inspectorates. 2) Voluntary OHS management systems are (mostly) proprietary products sold on the market and are to be verified by audits and certification schemes (Frick 2011).

Early voluntary management systems addressed safety only, i.e. not health, like the International Safety Rating (ISR) developed and distributed by the International Loss Control Institute (Georgia, USA) in the 1970s and 1980s. This system evolved into the International Safety Rating System (ISRS) which in a revised form is now distributed by Det Norske Veritas (DNV). The IRS has also laid the foundation for so-called 5-Star-programs. Many employers in, for example, Australia, North America and South Africa have used this program (Frick 2011). Other examples of voluntary systems are the British Standards Institute's OHSAS 18001, the Canadian Standards Association's CSA Z1000, the Chemical Industries Association's Responsible Care programme, the International Maritime Organisation's International Safety Management (ISM) Code and New Zealand's AS/NZS 484.

Companies may seek to limit exposure to uncertainty by joining business networks and agree on certain codes of good practice. Voluntary OHS management systems programs can therefore be seen as processes of so-called mutual or self-regulation where companies organise themselves in networks with shared minimum norms of acceptable behaviour. Frick and Zwetsloot (2007) suggest that OHSAS 18001's popularity in exporting countries is enhanced by the drive for corporate social responsibility (CSR), which makes consumer oriented corporations require their suppliers to demonstrate conformity with minimum labour and other standards.

Despite that voluntary OHS management systems have been in operation for decades and despite their apparent popularity only few evaluation studies exist. Intriguingly, some studies have raised concerns if the systems are able to 1) reduce the number of injuries, and, 2) audit and rate the pro-active efforts undertaken by company management. Quite obviously, such capabilities are 
essential if these systems should play a meaningful role, in self regulation or otherwise. Robson et al. (2007) concluded there was real knowledge gap in this area. They found insufficient evidence in the published, peer-reviewed literature on the effectiveness of voluntary OHS management systems to make recommendations either in favour of or against them.

The present paper makes a contribution to filling this gap by examining the association between implementation of the South African NOSA 5-Star Safety Management system and the rate of serious occupational injury for the period 1997-1999.

\subsection{History of the National Occupational Safety Association (NOSA)}

In the 1950s the South African Minister of Labour investigated ways of reducing wastage of manpower due to accidents. This led to the establishment in 1951 of the National Occupational Safety Organisation (NOSA) as a not-forprofit organisation, modelled on the Industrial Accident Prevention Association of Ontario (Canada). It was set up as a joint venture between the Workmen's Compensation Commissioner (WCC) and employers' associations and funded extensively by the State Accident Fund. NOSA has over the years been a major actor on the OHS scene is South Africa. It has developed a broad range of training courses offered to industry. The curriculum developed for its own people was eventually taken over by the Department of National Education and so established the National Diploma in Safety Management (Dekker 1990). NOSA has also published safety magazines and organized annual safety conferences. Funding from the State Accident Fund was gradually withdrawn after 1995 and NOSA became a fully privately owned company in 2000, generating income through training courses, seminars and audits (Walt 1999). After a liquidity crisis in 2005 , NOSA re-emerged under new private ownership (Hill 2005).

Of particular interest to this paper, NOSA has developed the so-called NOSA 5-Star Safety Management System with the stated dual purposes of directing companies' accident prevention activities and offering recognition of the extent to which excellence in safety management has been attained.

\subsection{The NOSA 5-Star System}

The NOSA 5-Star System owes much intellectual debt to other star rating systems, notably the International Safety Rating (ISR) developed by Frank Bird of ILCI, the International Loss Control Institute (Bird 1983) and in turn to the ideas of Herbert Heinrich (Hedlund 2011). Similar to the ISR, the NOSA system is also based on the idea of Management by Objectives. Objectives are set for management to attain and a 5-Star rating evaluation scheme has been developed to measure the extent to which the objectives have been met. "A one Star grading would indicate that a rather weak accident prevention programme is in operation whereas a five Star grading would indicate that it is one of the safest factories in the country" (Dekker 1990). Stars are awarded based on two 
criteria: The measurement of management's efforts to reach the objectives, called the effort leg, and the actual "disabling incident incidence rate" (DIIR) of the workplace, called the experience leg. Furthermore, some 5-Star companies can enter a regional competition. The winner is awarded with the so-called NOSCAR recognition which can be considered an elite sixth-Star bracket. ${ }^{1}$

The 5-Star System under study comprises 72 elements organised under five main sections. Elements are subdivided into about 300 components, sometimes also referred to as NOSA Minimum Standards. In order to guide the audit procedure each component is further specified into a number of Items for Consideration. A maximum point score is allocated to each of the 300 components. During the audit procedure, the NOSA auditor team assesses the level of compliance with each component and assigns a point score accordingly. The programme score is computed as the sum of actual scores divided by the maximum point score, which gives the effort rating, a number between 0-100 percent. The DIIR is computed as the number of "disabling incidents" per 200,000 hours worked, which gives the experience rating. The number of NOSA Stars is then determined from the criteria in Table 1.

Table $1 \quad$ Criteria for awarding NOSA Stars

\begin{tabular}{|l|l|l|l|}
\hline Star rating & $\begin{array}{l}\text { Effort } \\
\text { (percent) }\end{array}$ & $\begin{array}{l}\text { Experience } \\
\text { (DIIR) }\end{array}$ \\
\hline 5 Star - excellent & $\geq 91$ & and & $\leq 1$ \\
\hline 4 Star - very good & $\geq 75$ & and & $\leq 2$ \\
\hline 3 Star - good & $\geq 61$ & and & $\leq 3$ \\
\hline 2 Star - average & $\geq 51$ & and & $\leq 4$ \\
\hline 1 Star - fair & $\geq 40$ & and & $\leq 5$ \\
\hline
\end{tabular}

(Source: Audit Workbook, NOSA 1997)

The basic definition of a disabling incident (DI) is one in which one or more workdays or shifts were lost, i.e. a "disablement" of the worker's capability to carry out normal duties, as well as any incident covered by the Compensation for Occupational Injuries and Disease's Act (COID 1997). The definition is so shaped that, for example, reallocation of an injured worker to light duty will not circumvent that the incident be recorded as a DI. The full complexity of the procedure need not be covered in this paper, but it is important for the later

\footnotetext{
1 The so-called NOSCAR category (a play on the words NOSA Oscar) can for practical reasons be considered an elite 'sixth Star' bracket in the 'five-Star' system. Rules are complex but in short, only 5-Star companies that have a very high effort score of 95+, and no fatal injuries, are eligible to enter a Regional contest the coming year where they will be audited by a specially qualified team of NOSA auditors. Applicable Regions shall have at least 200 graded companies. At the end of 1999 there were seven such Regions comprising five South African geographic regions, a mining division and an international competition. The winner of a Regional contest is awarded the prestigious NOSCAR recognition. If awarded, the NOSCAR status can be retained for consecutive years, conditional that NOSCAR contest eligibility criteria remain fulfilled. Whenever eligibility criteria are violated the NOSCAR recognition is lost and the company must win a new Regional competition to regain it (Source: NOSA internal procedure MR05, appendix 1, rev 01, copy obtained Jan 25, 2000, and personal communication with NOSA auditors)
} 
discussion to note that the experience rating generally is based on the accident experience of the previous 365 days from the day of the audit. For smaller sites the DIIR computation may be based on a longer period. ${ }^{2}$

The system has been revised on a number of occasions. A major revision took place in 1996 with the inclusion of health issues and an increased attention to risk analysis techniques (Morice 1995). Another revision took place in 2000 introducing audit scores for environmental management to form an integrated safety, health and environmental management system. The system was stable over the period of study.

The five main sections of the NOSA system are 1) premises and housekeeping, 2) mechanical, electrical and personal safeguarding, 3) fire protection and prevention, 4) incident recording and investigation, and 5) health and safety organisation. The system and audit procedure are described in more detail in Hedlund (2002). An example from the Audit Workbook (NOSA 1997) illustrates the workings of the system:

Section 1.00 Premises and housekeeping

- Element 1.22 Good stacking and storage practices

- Component 1.22.2 Stacking neat, stable and controlled

- $\quad$ 1.22.2.a Stacks correctly erected $(\max$ height $=3 \mathrm{x}$ shortest base)

- $\quad$ 1.22.2.b Stacks bonded to prevent tumbling

Items for consideration under this component are: Who is responsible for safe stacking? What risks have been identified relating to unsafe stacking? What criteria are used to establish that persons responsible are qualified, trained and experienced?

The example highlights three important system characteristics. First, the emphasis on management bureaucratic controls. Second, the use of generic risk analysis approaches. Third, that the system also sets prescriptive standards to e.g. permissible stacking height, lifting tackle checklists, scaffolding inspections, to mention a few. The NOSA system hereby differs from other safety management approaches framed on quality management systems that deal extensively with broadly framed process standards, emphasizing management practices, action plans and continuous improvement, but have few, if any, prescriptive standards.

Because of the great number of system elements and the emphasis on bureaucratic controls and an auditable paper trail, companies usually have to

\footnotetext{
2 The purpose is not to disadvantage smaller companies. A work year corresponds to about 2,000 work hours. The DIIR definition implies that a company with about 100 workers can experience one DI per year and still meet the criteria for a 5-Star rating. Accidents are stochastic events and companies with fewer than 100 workers are therefore allowed to base their DIIR computation on a period longer than one year.
} 
employ a full time Safety Officer, who refers to the Site Manager or the CEO. The entire process thereby becomes driven by management. This is fully consistent with the Loss Control maxims that all accidents are caused by Lack of Management Control. But it also hints at low levels of employee participation. Workers are trained to follow safe procedures, but their advice or suggestions are generally not sought when such procedures are defined, a practice which is not uncommon in the South African context (Hedlund 2000).

\subsection{Critique of 5-Star systems}

While the 5-Star system is popular in South African industry (Hedlund 2011), occupational safety star rating systems have attracted searing criticism in international journals. Eisner and Leger (1988a) examined accident statistics of South African mines classified in the top 5-Star bracket of the International Mine Safety Rating (IMSR) scheme. They voiced concern if declining injury rates can be taken as proof of improvement in mine safety in the face of stable fatality rates. They argued that the decline in injury rates more likely was attributable to under-reporting and suggested that the IMSR scheme had motivated this ${ }^{3}$.

In another paper the same authors undertook a critical review of the International Safety Rating (ISR) system in South African mining (Eisner and Leger 1988b). The ISR scheme was a revised version of the IMSR scheme. They noted that the very competitiveness between mining companies engendered by the Star awards could lead to anything from, at best, wishful thinking to, at worst, falsification of records. The value of Star award schemes is therefore in doubt. Importantly, they found no correlation between the Star rating and accident rate. "Thus, whatever the effect of the ISR on mine safety, it does not appear to manifest itself in relative accident rates" (Eisner and Leger 1988b). In a similar vein, Lewis (1994) stated that there is no or little relationship between Star rating and death rate in the mining industry, and that there is no solid evidence that South African industry has been getting safer since NOSA began its work, referring to work of Leger and Macun (1990)..

The South African Public Commission of Inquiry into Safety and Health in the Mining Industry concluded that although safety management systems may have made some contribution to improving safety at some mines, they had become largely discredited in the eyes of those employed at the mines and in public perception, because of the very large disasters that continued to occur at mines with high Star ratings, and their imperceptible impact on the overall level of fatal and major injuries in South African mines. "While mining companies and mines must be free to use these systems if they feel they will assist them in improving health and safety, the Commission finds no basis for encouraging the adoption of these systems." (Leon et al., 1995, Vol 1:78).

\footnotetext{
${ }^{3}$ For sake of completeness, the Chamber of Mines responded to the critique in a later issue (Wagner 1988).
} 
Guastello (1991) undertook secondary analysis on accident experience data from South African gold mines, Australian coal mines and North American industry that employ the International Safety Rating (ISRS) scheme from ILCI. He also found that the ISR scheme "has no discernible effect on accident rates".

\subsection{A critical review of the critique}

Eisner and Leger (1988b) found no correlation between the Star rating and the accident rate of South African gold mines. Statistical tests are designed in a manner that a null-hypothesis is formulated and then sought rejected. In this case, the question is if accident rates are independent of the star rating, i.e. the null-hypothesis becomes: Accident rates are similar. Two kinds of statistical errors can be made. The first kind is to reject the null-hypothesis, when it is actually true. This is known as a Type 1 Error and is normally addressed by referring to a certain level of significance. The second kind of error, however, is to accept a null-hypothesis when it is actually wrong. This is known as a Type 2 Error and the statistical test itself provides no information on the magnitude of this error. Hence, any "conclusion" based on acceptance of the null-hypothesis is dubious.

A review of the conditions leading to Eisner and Leger's (1988b) finding will highlight this point. The authors observe that Star ratings of the mining companies have gradually increased so that most mines had achieved 4 or 5 Star status. They aptly term this phenomenon "Star-saturation". However, from a statistical point of view, this implies that the Star rating loses much of its predictive validity. They have to accept the null-hypothesis: accident rates are similar. This could be an artefact of the nature of the data, and the test, rather than the impact of the Star scheme. The same critique equally applies to the analysis by Guastello (1991) .

This paper will not enter a discussion whether 5-Star systems of the 1980s were able to improve workplace safety or not. Certainly, the exorbitant injury rates amongst black workers in South African mines in the 1980s suggest that safety management practices of that sector were not particularly advanced. Leger (1992:89) noted that at current accident levels, a black underground miner who spends twenty years underground faces a one in thirty chance of being killed and a risk of nearly one in two of being permanently disabled. A senior medical doctor at the National Centre for Occupational Health in Johannesburg said that they found people "dying from asbestosis inside the gates of 5-Star companies" (Hedlund 2002), indicative that health hazards were not considered.

\subsection{Justification for this study}

The papers referred to above have been relatively influential, partly because so few other studies have been carried out. In a frequently cited book, Nichols and Tucker (2000:304) observed that: "There is much testimonial support for

\footnotetext{
${ }^{4}$ Guastello (1993) retracted the earlier significance tests, though not on Type 2 error considerations.
} 
the efficacy of OHSM systems from promoters [...] and business users [...], but what little available empirical evidence there is paints a less rosy picture." The authors then refer to the 1988 papers. In a report prepared for the Australian National Occupational Health and Safety Commission on OHSM systems, several experts asserted "they don't work" although a more common position was that they could work, but "the jury is still out" (Gallagher et al. 2000).

In what they say is the first systematic literature review, Robson et al. (2007) investigated the effectiveness of mandatory and voluntary OHS management system interventions on employee health and safety outcomes. After screening out studies where the quality of evidence was rated "low" or "very low" only one single study (Bunn et al. 2001) was found to contain information relating changes in audit scores to changes in final OHS outcomes. An examination of this study reveals several weaknesses though. Much of the early criticism of 5Star systems would also apply to the Bunn et al. (2001) study, in particular the intervention's narrow focus on cost control (similar to Loss Control) and its blatant use of aggressive case management, return-to-work programs and socalled 'work hardening' schemes, conditioning employees for the physical demands of their job. To summarize, the priority given to primary prevention is not presented convincingly in the Bunn et al. (2001) study. Robson et al. (2007) concluded there was a real knowledge gap in this area. They found insufficient evidence in the published, peer-reviewed literature on the effectiveness of voluntary OHS management systems to make recommendations either in favour of or against them.

Robson and Bigelow (2010) intended to review the research evidence on the measurement properties of OHS management audits using the methods of systematic literature reviews but had to lower the study's ambitions due to a lack of published studies. The authors found only one study of construct validity in the literature on OHS audits that used statistical analyses - the Eisner and Leger (1988b) study on 5-Star systems. The authors noted that others before them have commented on the paucity of available research. "In 1988, Eisner and Leger remarked that 'A thorough search ... failed to discover any publication evaluating the [ISR] scheme' by academic authorities, even though the audit method was internationally recognized at the time. One decade later, Dyjack said he was 'unable to identify published studies evaluating the accuracy and repeatability of either publicly or privately held occupational health and safety assessment instruments'." (Robson and Bigelow 2010:S38). 


\section{Method}

\subsection{Methodological considerations}

The propensity to report occupational accidents, in particular the less serious ones, is influenced by social processes and other factors not related to safety. Four decades ago, the Lord Robens Committee noted that statistics based on length of absence from work were intrinsically unreliable. In comparison do statistics of fatalities and serious injuries provide more reliable indices of safety performance (Robens 1972:134-136). This is exactly the critique voiced by Eisner and Leger (1988a) who pointed to a discrepancy between lost-time incident and fatality rates, and by Lewis (1994), who said that the NOSA system encourages aggressive monitoring of accident claims rather than addressing basic accident causes. This type of critique can only be addressed if the evaluation measure is serious injury, the reason why this study only considers fatal accidents and permanently disabling accidents (loss of a limb etc.) as measures of safety performance.

The rare occurrence of those events has important methodological implications. The number of work injuries that occur over a period of time is commonly described by the Poisson statistical distribution. Because the standard deviation is the square root of the mean for this distribution, a large number of injuries and hence a large sample are required before a difference in performance will show as statistically significant, i.e. before the risk of committing Type 2 Errors is small. It must therefore be expected, a priori, that a survey of serious OHS outcomes will have limited ability to demonstrate significance.

The ideal evaluation study is one in which companies are allocated at random to either treatment or control conditions (Shannon et al. 1999). In the face of the considerable effort, time and associated costs involved in implementing the NOSA system and the large sample size required, the ideal design is beyond reach. If the NOSA 5-Star System were effective, the stated objective of accident prevention should manifest itself in lower rates of serious injury in NOSA companies than in the industry as a whole. A test of this hypothesis would be within reach, given this study's financial and practical constraints.

The DIIR metric used in the determination of the NOSA Star-rating relates to injuries causing lost work time and is insensitive to the severity of the injury. NOSA auditors do not request information specifically on fatal and permanently disabling incidents. NOSA can therefore not provide OHS 
outcome data of interest to this study. In theory, this kind of information could be available from the Workmen's Compensation Commissioner (WCC). Hedlund (2002) attempted to do so, but faced various complications; in part because the NOSA audit concerns a work site, whereas the WCC holds registrations for entities that often comprise multiple sites; in part because WCC statistics are only available with a considerable delay. In practice therefore, information on fatal and permanently disabling incidents have to be retrieved directly from the companies through self-reporting.

\subsection{Data collection procedure}

A cross-sectional postal survey was undertaken. The universe was defined as all companies in the manufacturing industry, which had been Star-rated by NOSA at least once during the 3-year period 1997-1999.

Records were received from ten NOSA office locations from which a list of companies was created. Some companies were only purchasing training, not auditing, services, or were on the lists for other reasons. Companies with no audits in the 3-year period of interest or with a postal address outside South Africa were taken off the list. Each list entry was then examined in order to determine if it was in the manufacturing sector, defined as SIC categories 6-14 in the Workmen's Compensation Commissioner's annual statistics. This process eventually identified a universe comprising 399 companies.

A questionnaire was mailed, attention "The Safety Officer or the General Manager", soliciting their Star-rating, number of employees, and number of fatal and permanently disabling injuries for each of the years 1997, 1998 and 1999, and other information. Much effort was put into obtaining a high response rate. Enclosed with the questionnaire was an endorsement letter signed by the NOSA CEO and a reply envelope to the author's work address with an identification number printed on the reply address label. Up till 3 reminder letters were sent to non-responding companies in follow-up activities. Companies that returned incomplete or conflicting information, and had used the reply envelope, were contacted telephonically in an attempt to identify the respondent and clarify the response. The questionnaire activity took place March 2000 - July 2000.

The records received from the ten geographical NOSA offices also comprised basic information on some audits. The data were clearly incomplete, with many registrations for 1998, some for 1997 and 1999, and occasionally for earlier years. It was possible to extract basic data on 1,963 audits (Star-rating, audit score, DIIR, number of employees and SIC category), though often with some fields blank. This data set, henceforth the Basic Data Set on Audits, may serve as a crude population reference group and help determine if the companies that returned the questionnaire (the sample) were representative for all NOSA rated manufacturing companies (the population). 

and the incidence of fatal and permanently disabling injury

NOSA kindly provided records, an endorsement letter and access to audits, but has otherwise not been involved in or contributed to this study, directly or indirectly. 


\section{$3 \quad$ Results}

\subsection{Response rate}

251 companies returned the postal questionnaire, equivalent to a 63 percent response rate. Seventeen companies indicated that they were not in the manufacturing sector or had not been audited, reducing the number of useful questionnaires to 234 . The companies reported that 592 audits had taken place during 1997-1999.

\subsection{Population properties}

Analysis of the Basic Data Set on Audits shows that NOSA audits more manufacturing than non-manufacturing companies and that manufacturing companies generally receive a higher Star-rating (Figure 1), the finding is statistically significant. ${ }^{5}$ The data also show some evidence of "Star-saturation" with about 70 percent of all Star-ratings for manufacturing being in the top Star brackets, 4-Star or more. If the Basic Data Set on Audits is taken as a population reference group, analysis shows that the sample of NOSA manufacturing companies that returned the questionnaire have higher Starratings than NOSA rated manufacturing companies in general (Figure 2) - i.e. companies with a low Star-rating had a low response rate. The finding is statistically significant. ${ }^{6}$

\footnotetext{
5 Two distributions of awarded Stars are examined: 1) for companies in SIC categories 614 (manufacturing); and 2) all other companies, including those with missing SIC category. Null hypothesis: $\mathrm{H}_{0}$ : distributions are similar, rejected $(\mathrm{P}<0.001)$ using a WilcoxonMann-Whitney test.

6 Two distributions of awarded Stars are examined: 1) for companies in the Basic Data Set on Audits that are in manufacturing; and 2) companies that returned the postal questionnaire. Null hypothesis: $\mathrm{H}_{0}$ : distributions are similar, rejected $(\mathrm{P}<0.001)$ using a WilcoxonMann-Whitney test.
} 

and the incidence of fatal and permanently disabling injury

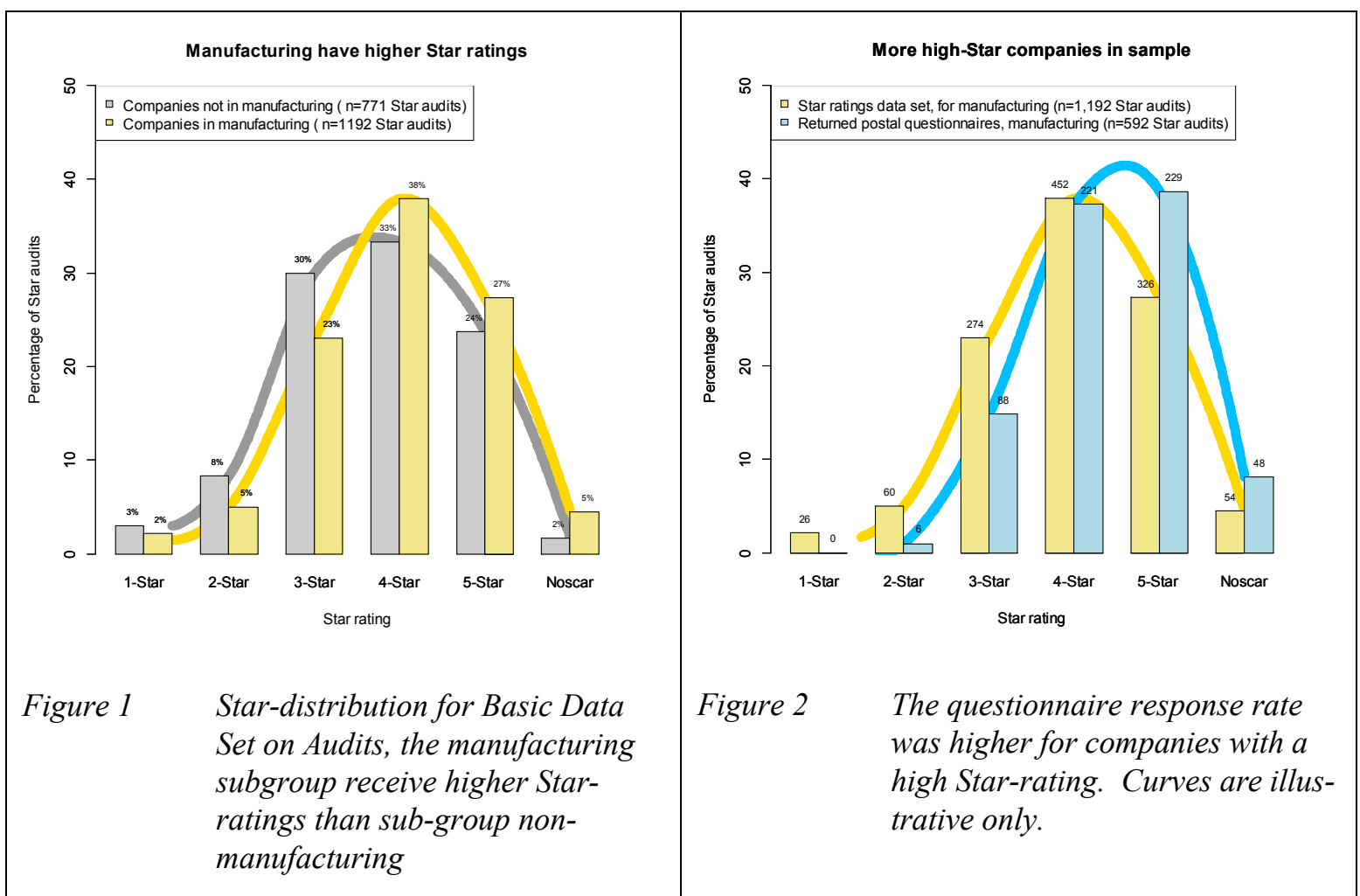




\section{More large companies returned postal questionnaire}

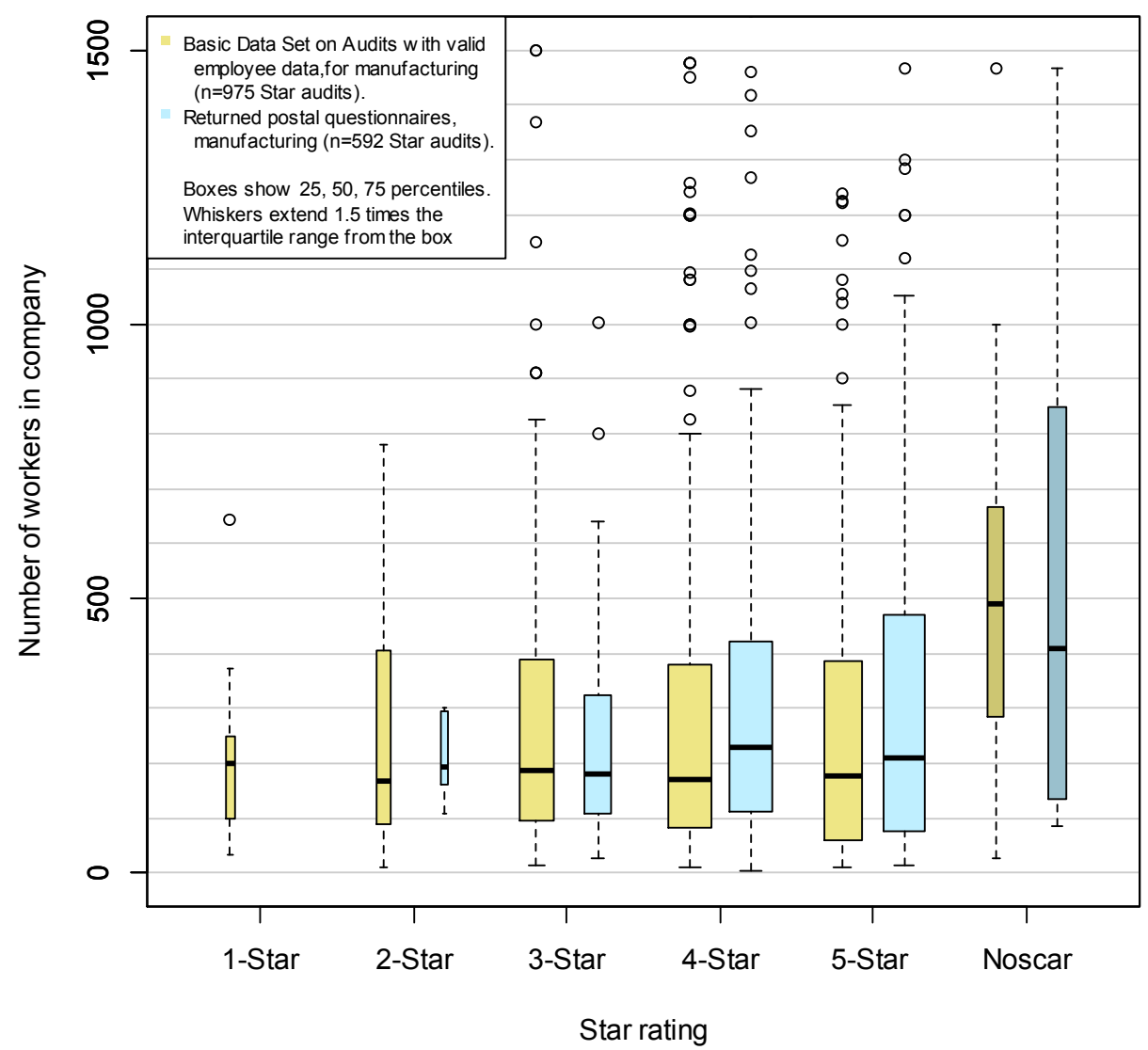

Figure $3 \quad$ The postal questionnaire response rate was higher for companies with many employees. NOSCAR companies are larger than companies in other Star-brackets. Width of bars indicate number of observations in group.

For the population, manufacturing companies awarded the elite NOSCAR rating have significantly ${ }^{7}$ more employees (median 489 employees) than companies in the 1-5 Star-brackets (median 176 employees), see Figure 3 . A similar conclusion was reached for the questionnaire sample data. The 4-Star and 5-Star companies that returned the questionnaire are slightly larger (median 228 and 209 employees) than 4-Star and 5-Star companies in the population (median 171 and 176 employees). Both findings are significant at close to the $\mathrm{P}=0.01$ level. ${ }^{8}$ While the differences are statistically significant an inspection

\footnotetext{
${ }^{7}$ The Basic Data Set on Audits was divided into two groups, NOSCAR companies and companies with a 1-5 Star-rating. Null hypothesis: $\mathrm{H}_{0}$ : the distribution of number of employees in both groups are similar, rejected $(\mathrm{P}=0.001)$ using a Wilcoxon-Mann-Whitney test. For Star-brackets 1-5, intergroup differences with respect to number of employees were not significant.

${ }^{8}$ Again using the two-sided Wilcoxon-Mann-Whitney test.
} 
of Figure 3 would indicate that the overall correspondence between the sample and the population is fine.

\subsection{Imputations}

Although companies are expected to be audited every year, 76 companies (32 percent) in the postal questionnaire sample did not report a full 3-year audit history. Some of the companies that were contacted telephonically stated major organisational restructuring processes such as acquisition of another company, downsizing of own organisation, moving to new premises, etc., as reasons for letting their rating lapse. Many companies with lapsed 5-Star ratings said they for all practical reasons had maintained the NOSA system. Other reasons for not having a full 3-year audit record were recent introduction or abandoning of the NOSA system.

A key objective of the survey is to determine the number of serious accidents that had taken place each calendar year over the 3-year period and the corresponding Star rating and the number of employees exposed to the workplace hazards. An incomplete audit pattern may introduce systematic bias. For example, the five-Star Company A skipped an audit in 1998, the same year the company experienced a fatal injury (Table 2). Bearing in mind the considerable effort required to implement the NOSA system and to maintain a high Star-rating, it is reasonable to pool the performance of this company with that of other 5-Star companies. A parallel situation exists for Company B (Table 2), which seems to have introduced the NOSA system in 1998 and attained a 3-Star entry rating, but skipped the audit in 1999, the year it experienced a fatal injury.

Why would companies let their Star-rating lapse if they experience injuries? As stated earlier, NOSA auditors request the company's accident performance of the past 365 calendar days, when computing the DIIR lost-time metric. If companies fear that the occurrence of a fatal accident may have a negative influence on the auditors' scoring of the company's effort (the audit score) it could be attractive to let the Star-rating lapse to maintain a clean 365 days history window. Hedlund (2011) reports the results of participant observation during NOSA audits and describes a case where the company safety officer successfully concealed the deaths of two contractors from the NOSA auditors simply by letting the Star-rating lapse.

Star-ratings were imputed according to this procedure: a 3-Star rating can be extended one year forwards, a 4-Star one year forwards and one year backwards, a 5-Star two year forwards and one year backwards, and a NOSCAR Star two year forwards and backwards. This procedure is slightly different than the one reported in Hedlund (2002). 
Table $2 \quad$ Examples of skipped audits in questionnaire sample

\begin{tabular}{|l|l|l|l|}
\hline & 1997 & 1998 & 1999 \\
\hline Company A & & & \\
\hline Number of fatal injuries & 0 & 1 & 0 \\
\hline Number of permanently disabling injuries & 0 & 0 & 0 \\
\hline Star rating & 5 & not rated & 5 \\
\hline Company B & & & \\
\hline Number of fatal injuries & 0 & 0 & 1 \\
\hline Number of permanently disabling injuries & 0 & 0 & 0 \\
\hline Star rating & not rated & 3 & not rated \\
\hline
\end{tabular}

\subsection{Reference group}

Hedlund (2013) examined the accident performance of the South African manufacturing industry and reported various complications in extracting reliable statistics for the period of interest. Two sources of accident statistics are available, from the Department of Labour (DOL) and the Workmen's Compensation Commissioner (WCC). The two sources differ in scope. DOL registrations exclude road accidents arising out of employment, but include contractor incidents at company premises. WCC registrations include road accidents arising out of employment, but exclude contractors injured at company premises because they are not insured by the company (and perhaps not insured at all).

NOSA's procedure for computing the DIIR aligns broadly with WCC criteria with the important difference that NOSA also includes contractor accidents whereas WCC does not. Unfortunately, little is known about the number of contractor incidents that are lost from WCC statistics and currently no reliable basis exists for making adjustments. In addition, Hedlund (2013) argued that the number of reported fatal injuries in 1999, the most recent WCC statistical publication, appeared unusually low. With the caveat that WCC statistics probably underestimate the actual performance of the reference group, available key statistics are presented in Table 3.

Table $3 \quad$ Accident experience of reference group

\begin{tabular}{|c|c|c|c|c|c|}
\hline \multirow[t]{2}{*}{$\begin{array}{l}\text { Calendar } \\
\text { year }\end{array}$} & \multirow[t]{2}{*}{$\begin{array}{l}\text { Employee } \\
\text { years }^{\text {a }}\end{array}$} & \multicolumn{2}{|l|}{ Fatal injury } & \multicolumn{2}{|c|}{$\begin{array}{l}\text { Permanently disabling } \\
\text { injury }\end{array}$} \\
\hline & & $\begin{array}{l}\text { Number of } \\
\text { injuries }{ }^{b}\end{array}$ & $\begin{array}{l}\text { Incidence } \\
\text { rate }^{c}\end{array}$ & $\begin{array}{l}\text { Number of } \\
\text { injuries }\end{array}$ & $\begin{array}{l}\text { Incidence } \\
\text { rate }^{c}\end{array}$ \\
\hline 1997 & $1,395,636$ & 197 & - & 2,908 & \\
\hline 1998 & $1,339,888$ & 197 & - & 2,617 & \\
\hline 1999 & $1,314,488$ & 126 & - & 1,826 & \\
\hline Total & $4,050,012$ & 520 & 1.28 & 7,351 & 18.15 \\
\hline \multicolumn{6}{|c|}{$\begin{array}{l}\text { Source: Hedlund (2013) } \\
\text { a Bulletin employment data } \\
\text { b If regression equation ( } 3 \text { ) in Hedlund (2013) is used, the total number of fatal injuries com- } \\
\text { putes to } 522 \text {, the lower figure of } 520 \text { is used here. } \\
\text { c Incidence rate pr } 10,000 \text { employees per year }\end{array}$} \\
\hline
\end{tabular}




\subsection{Accident experience of questionnaire sample companies}

Table 4 presents the number of fatal and permanently disabling injuries and the number of man-years worked. The entire sample has a lower incidence of fatal injuries than the reference group, the finding is significant at the $\mathrm{P}=0.09$ level. Only the performance of NOSCAR companies attains a high level of statistical significance at $\mathrm{P}=0.003$. With regard to permanently disabling injuries, NOSA companies clearly have fewer such accidents than the reference group, the finding is significant at the $\mathrm{P}<0.001$ level. In conclusion, there is empirical evidence that NOSA manufacturing companies have fewer fatal injuries than the national average for manufacturing, and strong empirical evidence that they have fewer permanently disabling injuries. 
The relationship between the implementation of voluntary Five-Star occupational health and safety management system and the incidence of fatal and permanently disabling injury

Table 4

Accident experience of survey sample companies 1997-1999 and significance testing

\begin{tabular}{|c|c|c|c|c|c|c|c|c|}
\hline \multirow{2}{*}{$\begin{array}{l}\text { Star } \\
\text { category }\end{array}$} & \multicolumn{4}{|c|}{ Fatal injury } & \multicolumn{4}{|c|}{ Permanently disabling injury } \\
\hline & $\begin{array}{l}\text { Observed } \\
\text { employee } \\
\text { years }\end{array}$ & $\begin{array}{l}\text { Observed } \\
\text { number of } \\
\text { injuries }\end{array}$ & $\begin{array}{l}\text { Expected } \\
\text { number of } \\
\text { injuries }^{b}\end{array}$ & $\begin{array}{l}\mathrm{H}_{0}: \mathrm{Ob}- \\
\text { served }>= \\
\text { Expected } \\
(\mathrm{P} \text {-value }) \\
\mathrm{c}\end{array}$ & $\begin{array}{l}\text { Observed } \\
\text { employee } \\
\text { years }^{d}\end{array}$ & $\begin{array}{l}\text { Observed } \\
\text { number of } \\
\text { injuries }\end{array}$ & $\begin{array}{l}\text { Expected } \\
\text { number of } \\
\text { injuries }^{b}\end{array}$ & $\begin{array}{l}\mathrm{H}_{0}: \mathrm{Ob}- \\
\text { served }>= \\
\text { Expected } \\
(\mathrm{P} \text {-value }) \\
\mathrm{c}\end{array}$ \\
\hline 1-Star & - & - & - & & - & - & - & \\
\hline 2-Star & 1,251 & 0 & 0.2 & & 1,251 & 6 & 2.3 & \\
\hline 3-Star & 40,624 & 5 & 5.2 & & 24,624 & 20 & 44.7 & $<0.001$ \\
\hline 4-Star & 99,944 & 15 & 12.8 & & 74,716 & 28 & 136 & $<0.001$ \\
\hline 5-Star & 105,097 & 9 & 13.5 & 0.136 & 97,179 & 45 & 176 & $<0.001$ \\
\hline NOSCAR $^{a}$ & 45,918 & 0 & 5.9 & 0.003 & 32,918 & 8 & 59.7 & $<0.001$ \\
\hline Total & 292,834 & 29 & 37.6 & 0.089 & 230,688 & 107 & 419 & $<0.001$ \\
\hline \multicolumn{9}{|c|}{$\begin{array}{l}\text { a NOSCAR is an elite "6-Star" bracket in the 5-Star system. } \\
\text { b Assuming incidence rate of reference group. } \\
\text { c Computed directly from Poisson distribution. } \\
\text { d Some companies reported the number of fatal injuries, but not the number of permanently disabling injuries, in partic- } \\
\text { ular for the early years in the period. There are therefore fewer employee man-years for the permanently disabling inju- } \\
\text { ry category than for the fatal injury category. }\end{array}$} \\
\hline
\end{tabular}

Table $5 \quad$ Computed injury incidence rates for survey sample companies 19971999 including confidence intervals

\begin{tabular}{|c|c|c|c|c|c|c|}
\hline \multirow{3}{*}{$\begin{array}{l}\text { Star } \\
\text { category }\end{array}$} & \multicolumn{6}{|c|}{95 percent confidence intervals ${ }^{a b}$} \\
\hline & \multicolumn{3}{|c|}{ Fatal injury } & \multicolumn{3}{|c|}{ Permanently disabling injury } \\
\hline & $\begin{array}{l}\text { Lower } \\
\text { bound }\end{array}$ & $\begin{array}{c}\text { Ob- } \\
\text { served }\end{array}$ & $\begin{array}{l}\text { Upper } \\
\text { bound }\end{array}$ & $\begin{array}{l}\text { Lower } \\
\text { bound }\end{array}$ & $\begin{array}{c}\text { Ob- } \\
\text { served }\end{array}$ & $\begin{array}{l}\text { Upper } \\
\text { bound }\end{array}$ \\
\hline$<=3-$ Star & 0.24 & 1.19 & 2.39 & 6.57 & 10.0 & 13.9 \\
\hline 4-Star & 0.80 & 1.50 & 2.30 & 2.41 & 3.75 & 5.22 \\
\hline 5-Star & 0.38 & 0.86 & 1.43 & 3.29 & 4.63 & 6.07 \\
\hline NOSCAR & 0 & 0 & $0.65^{\mathrm{C}}$ & 0.91 & 2.43 & 4.25 \\
\hline$<=4-$ Star & 0.85 & 1.41 & 2.04 & 3.98 & 5.37 & 6.86 \\
\hline 5-Star & 0.38 & 0.86 & 1.43 & 3.29 & 4.63 & 6.07 \\
\hline NOSCAR & 0 & 0 & $0.65^{\mathrm{c}}$ & 0.91 & 2.43 & 4.25 \\
\hline \multicolumn{7}{|c|}{$\begin{array}{l}\text { a Incidence rates are per } 10,000 \text { workers per year. } \\
\text { b Computed directly from Poisson distribution, two-tailed. } \\
\text { c Upper confidence bound when no events are observed are computed using the 'rule of } \\
\text { threes', which coincides with the upper limit of a one-tailed } 95 \% \text { confidence interval from the } \\
\text { Poisson distribution. }\end{array}$} \\
\hline
\end{tabular}

How well the Star rating can predict the incidence of serious injury is a measure of criterion validity. Table 5 presents computed confidence intervals for fatal and permanently disabling injury for different Star brackets. Because of the low number of observations the lower Star categories were pooled into a single bracket. Results are shown in Figure 4. The internal ranking in plots a) and d) is not fully consistent, with 3-Star companies (perhaps) having fewer fatal accidents than 4-Star companies; and 4-Star companies having fewer 
permanently disabling injuries than 5-Star companies. It is notable however, that any line drawn through all confidence intervals will, for both injury types, exhibit a negative slope. It is thus concluded that the NOSA Star rating is a sound, although imperfect, predictor of injury rates. Plots b) and d) shows what happens if Star categories 4 and fewer are pooled into a single bracket. The internal ranking becomes fully consistent, fatal injuries maintain a significant negative slope, but significance is lost for permanently disabling injuries (confidence intervals overlap).

In conclusion, the data offer support to the original claim by NOSA that "a 5Star grading would indicate that it is one of the safest factories in the country".
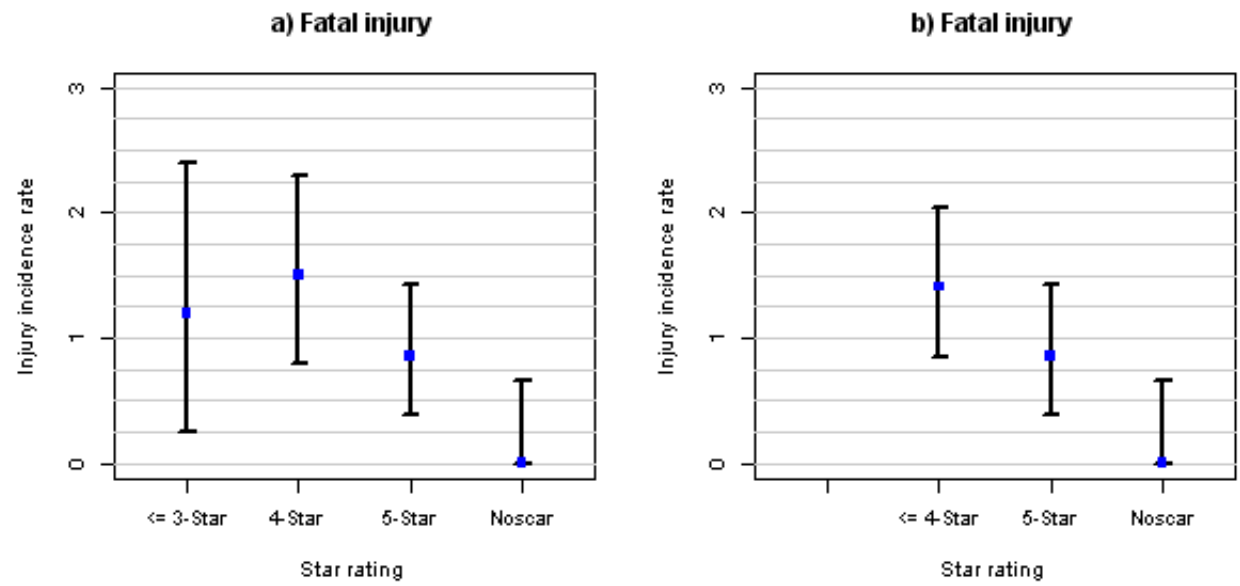

c) Permanently disabling injury

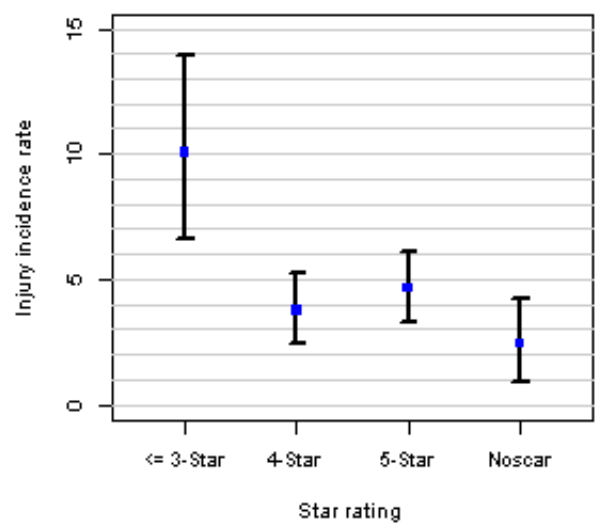

d) Permanently disabling injury

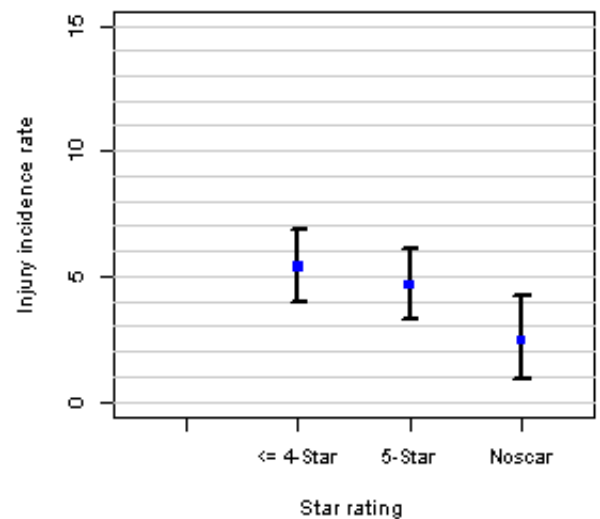

Figure $4 \quad$ Computed incidence rates and 95 percent confidence intervals for serious occupational injury. In plots b) and d) 3-Star and 4-Star-ratings are pooled into a single bracket. The Star rating is a sound, although imperfect, predictor of injury rates 


\section{Discussion}

\subsection{Potential errors in survey sample data}

Intermediate analysis of returned questionnaires revealed that some respondents explicitly noted that their reported fatal injury was a traffic accident occurring on a public road. The NOSA definition of a Disabling Injury comprises any incident covered by the COID Act, which does include accidents on public roads if they arise out of employment. They are therefore to be included in the questionnaire's injury experience section. However, the explicit mentioning of a road accident could indicate a perceived unfairness on the part of the respondent, that the company's accident record is burdened by events over which management, arguably, has little or no control. This raised the concern if a less experienced respondent would omit reporting road injuries and thereby introduce a systematic downward bias in the sample data. Traffic accidents are a potentially significant source of error as about 40 percent of all fatalities in the manufacturing industry reported to the WCC are classified as vehicle accidents, i.e. accidents that involve a vehicle regardless of whether the accident occurs on company premises or on public roads (Hedlund 2013). In the last follow-up campaign, non-responding companies were sent a revised questionnaire with an additional question: if they would include road accidents in their reported injury figures. 28 companies (76 percent) replied Yes, 7 replied No, and 2 replied Don't know. The sample fatality figures could perhaps be underreported with up to about 10 percent $(0.24 * 0.4)$; in this case the overall significance level in Table 4 would change from $\mathrm{P}=0.09$ to $\mathrm{P}=0.16$.

A similar potential error was identified regarding noise induced hearing loss (NIHL), which in the COID Act is classified both as a disease and as a permanently disabling injury. A less experienced respondent might erroneously omit reporting of NIHLs on the grounds that it is a disease, not an injury, introducing a systematic downward bias. However, only very few NIHLs are reported to the WCC and potential errors of exclusion appear negligible. The inclusion of NIHLs might rather well introduce a systematic upward bias because companies with advanced OHS management systems would more likely identify, record and notify the compensation commissioner (and hence NOSA auditors) of this condition, i.e. precisely the companies with high Star ratings.

The questionnaire method relies on the respondent's ability to correctly recall events 3 years back in time. Some companies reported the number of fatal 
injuries, but not the number of permanently disabling injuries, in particular for the early years in the period. Potential reasons for this could be inability to recall the correct number, for instance due to short tenure of the respondent, or due to inconvenience if it would require retrieval of old records. Less than 20 percent of the respondents reported a tenure of 0-4 years, however. The potential impact on the number of fatal accidents reported for the three-year study period is likely minor; due to the traumatic nature of such serious accidents the knowledge will remain in corporate memory for longer than this.

The most significant error is probably related to mistakes in filling out the questionnaire form. Postal questionnaires are blunt data collection instruments and during telephone follow-up activity many mistakes were discovered, for instance that a secretary had intercepted and filled out the questionnaire (with errors) on behalf of the safety manager, or that a hurried respondent had entered the much larger numbers for NOSA disabling incidents (lost-time), not permanently disabling incidents. Only a few of such undiscovered mistakes may inflate the survey data significantly.

\subsection{No control group}

The ideal evaluation study is one in which companies are allocated at random to either treatment or control conditions (Shannon et al. 1999). The present non-experimental design does not meet this high standard. Statistical associations and causal inferences regarding the ability to improve safety performance can therefore, strictly speaking, not be made. It could be the case that only the safer industries find the NOSA system attractive and that this select group has a lower accident rate than the national average regardless of whether a NOSA system is in place or not. It does not seem very likely though, as many of the survey sample respondent companies were industrial enterprises with obvious work hazards, such as foundries, metal die casting, cold forging and other metal working operations, wooden furniture production, chemicals, ammunitions and explosives manufacturing. Nevertheless, because there is no control group the possibility remains that the relationships reported here simply reflect some factor not controlled for.

\subsection{Accident rates for reference group}

As stated earlier, the WCC statistics probably underestimate the actual performance of the reference group because contractor injuries are systematically excluded from this data source. It is remarkable that NOSA companies hardly have fewer fatal accidents than the reference group and at the same time have a much better performance when the outcome is permanently disabling incidents. This could be due to inaccuracies in the WCC statistics or it may reflect that fatal accidents have a different causation than non-fatal as suggested by Salminen et al. (1992). 


\subsection{Distortions due to the voluntary nature of NOSA auditing}

The internal ranking in plots a) and c) (Figure 4) is not fully consistent, with 3Star companies (perhaps) having fewer fatal accidents than 4-Star companies; and 4-Star companies having fewer permanently disabling injuries than 5-Star companies.

A possible explanation could be that 3-Star companies are less committed to the NOSA system and simply opt to abandon it if they experience a fatal injury. Similarly, the permanently disabling injury rate for the 4-Star category is lower than that for the 5-Star category. The registration of noise induced hearing losses could be a possible explanation if the higher star companies are more likely to identify and register that type of injury correctly.

The most prominent source of distortion may be associated with the fact that auditing is an entirely voluntary activity. For example, it may be speculated if companies with mediocre safety activities are more likely to opt to abandon or pause the auditing scheme in the event that they experience a (rare) serious injury. Assuming that they will generally be rated a low Star rating due to a low score on the "effort leg" they will as a group have a (biased) low number of injuries thus distorting the predictive validity. This type of behaviour may be difficult to handle in a voluntary system without also setting strong negative incentives for mediocre bona-fide companies to embark on the system.

The research reported here was part of a larger project and other data collection efforts took place, including attitude statements enclosed with the postal questionnaire, participant observation, and others. The results are reported elsewhere (Hedlund 2002, 2011). The attitude statements were worded as concise assertions and respondents were asked to mark the extent to which they agreed or disagreed using a four-point Likert scale. Companies with a superficial or a non-genuine commitment to safety would be expected to answer affirmatively to the question (Q34) "Safety works until we are busy, then other things take priority". A considerable minority of one out of three respondents conceded that this was the case. The respondents generally had a positive view of the diligence and thoroughness of the NOSA 5-Star system. A majority (72\%) of the respondents disagreed with the statement (Q12) "We could hide a sensitive safety issue from a NOSA auditor, if we wanted to do so."

Spearman correlation coefficients were computed to reveal significant associations. A high Star-rating, and hence a better accident performance, was positively associated with a high tenure of the respondent $(\mathrm{P}<0.001)$ and positively associated with the company's overall attitude to safety (Q34), $(\mathrm{P}=0.004)$

The sizable minority of companies that expressed they could deceive the NOSA auditors, hiding sensitive issues (Q12), had a poor safety attitude score (Q34) $(\mathrm{P}<0.001)$, indicative that their preventive safety efforts were lacking and they indeed could have a motive to try to hide things. Yet, their Star rating did not 
appear to be negatively influenced by their lacking safety efforts, the association was negative but far from significant $(\mathrm{P}=0.61)$. The correlation analysis therefore offers some credibility to their claim, that they are able to deceive auditors. Hence, intentional and successful deception of auditors by a sizable minority is a possible explanation for the imperfect relationship between the Star-rating and the accident performance.

Methodological problems in evaluating accident prevention programmes abound. The overall conclusion, however, is the Star rating is a sound although imperfect predictor of injury rates.

\subsection{Implications for voluntary OHS management systems}

How should the results be interpreted in a broader context? Voluntary OHS management systems are in very widespread use and have evidently come to stay. At the same time, there is a continuous flow of disconcerting evidence, suggesting occasional failure. In December 2012, a textile factory in Karachi, Pakistan, burned quickly, killing at least 262 workers. Safety conditions were appalling with locked emergency exits and barred windows that prevented workers from leaping to safety. Yet, just three weeks before the blaze the factory was awarded a SA8000 certificate, one of the most prestigious in the industry, issued under the auspices of Social Accountability International, created to set and safeguard baseline standards for supply-chain workers in poor countries, particularly those with corruption-prone governments and weak unions. A SA8000 certificate is meant to signal that the factory meets basic requirements in eight areas, including health and safety, wages, working hours and child labour (Walsh and Greenhouse 2012).

A fatal accident in a Swedish plant occurred just after DNV had certified its management system. The subsequent labour inspection inquiry established that the fatality was caused by systematic management mistakes. In the ensuing debate, DNV claimed to have certified only the existence of a management system, not that it was implemented in practice (Frick 2011).

The sporadic failures of voluntary OHS audit systems pale however, when compared to the occasional dysfunction of voluntary audit systems in other sectors. In their report, the financial crisis inquiry commission concluded that the credit rating agencies were key enablers of the financial meltdown (FCIC 2011:xxiv). Their job was to provide an objective analysis of the risk posed to investors. Sellers of securities, who paid the credit rating agencies for their assessment work, were interested in high ratings because certain investors like retirement funds were required by law or charter only to hold investment-grade securities. This system broke down, as hundreds of billions of dollars of assets later shown to be worthless received high ratings from the agencies.

Christopher Cox, the head of the U.S. Securities and Exchange Commission, a long-time proponent of deregulation, said that the financial crisis had "made it abundantly clear that voluntary regulation does not work". The fact that investment bank holding companies could withdraw from voluntary 
supervision at their discretion diminished the perceived mandate of the program, and weakened its effectiveness (Labaton 2008). The accounting scandals at Enron and WorldCom, surpassing each other as the largest bankruptcies in U.S history has also tarnished the value of (mandatory) accounting audit practices and the reputation of celebrated accountancy firms.

A cautious conclusion would therefore be that voluntary OHS audit systems are embedded in structural problems that set limits to what they can reasonably be expected to accomplish. The fundamental issues are about naivety and the intrinsic viability of self-regulation. In this light, the NOSA Star system would appear to do quite well indeed.

This study will not enter a discussion if the early critique of South African 5Star systems was justified or not. Bearing in mind the conclusions of the Leon Commission on mining referred to earlier, the critique may have influenced government policy and led to the decision to withdraw public funds from NOSA. To the extent that this weakened the work of NOSA, culminating with a liquidity crisis in the mid-2000s, the critique would seem to have done a disservice to occupational safety in South Africa, despite intentions to the contrary. 


\section{Conclusion}

The NOSA 5-Star System is a voluntary combined safety management system and audit scheme. The safety management system is of the Loss Control type based on the theories of Heinrich. The objective of the audit scheme is to measure the effectiveness of the management system's accident prevention programme and award stars based on two criteria: a) a pro-active measure based on the comprehensiveness of the accident prevention programme, the socalled the effort leg, and, b) a reactive measure based on the actual lost-time incident frequency rate, the so-called the experience leg.

This study finds that South African manufacturing companies, which were committed to the NOSA system in its 1997-1999 version, experienced fewer fatal and permanently disabling injuries than the reference group, the national average of manufacturing companies. Overall, it appears plausible that this is due to the systematic prevention programme of the NOSA system.

This study also finds an inverse correlation between the Star rating and the serious injury incidence rate. Companies with high star ratings have lower fatal and permanently disabling injury rates than companies with low star ratings. It is concluded that the Star rating is a sound although imperfect predictor of injury rates. The fact that auditing is an entirely voluntary activity likely distorts the Star rating to some extent. For example, it is speculated that some (unsafe) companies may abandon or pause the auditing scheme if they experience too many injuries. There is also some evidence to suggest that companies with poor safety attitudes are able to deceive auditors.

Methodological problems in evaluating accident prevention programmes abound. However, the results of this study indicate that voluntary OHS management systems are capable of improving firm's accident performance but also that the audit systems are imperfect and seem at least partly incapable of handling partial disclosure of information and intentional deception. The problem likely resides in an inherent information asymmetry, that the audited party has more and better information than the auditing party. Contributing factors may be a power imbalance and conflicts of interest; the auditors have few sanctions, they are paid by the audited party and they have no interest in estranging the business relation with the audited party.

This may be an unwelcome result for the viability of mutual regulation. In a broader view however, the adoption of such systems might well be endorsed by policymakers, because their positive impact on OHS performance could be 

and the incidence of fatal and permanently disabling injury

substantial when aggregated over an entire country. It is clear though, that such systems cannot substitute authority enforcement activities at company level. 


\section{Acknowledgements}

A large amount of basic data collection and analysis took place in South Africa 1999-2000 financed by a PhD grant from DANCED/DUCED and Aalborg University, Denmark. Without the steady support of Prof. Per Christensen, this work would not have completed. All statistical computations were carried out using the free software $\mathrm{R}$, version 2.15.2 


\section{$7 \quad$ References}

Bird F.E. (1983) The development of the International Mine Safety Rating Loss Control Survey 2(4):10-11, A Chamber of Mines publication, South Africa

Bunn WB, Pikelny DB, Slavin TJ, Paralkar S (2001) Health, Safety, and Productivity in a Manufacturing Environment. Journal of Occupational \& Environmental Medicine. 43(1):47-55, January 2001

COID (1997) Compensation for occupational injuries and diseases Act no. 130 of 1993, as amended by Act no. 61 of 1997. Statutes of the Republic of South Africa (33):33-131

Dekker, L.D. (1990) Statutory institutions of the Department of Manpower - A sufficient base for a labour market council Wits Business School and Institute for Industrial Relations, Johannesburg, South Africa ISBN 0-908414-28-5

Eisner H.S. and Leger J.-P. (1988a) Safety in South African mines: An analysis of accident statistics. Journal of the South African Institute of Mining and Metallurgy 88(1):1-7

Eisner H.S. and Leger J.-P. (1988b) The international safety rating system in South African mining Journal of Occupational Accidents 10: 141-160

FCIC (2011) Final Report of the National Commission on the Causes of the Financial and Economic Crisis in the United States. Financial Crisis Inquiry Commission. Official Government Edition. January 2011

Frick K (2011) Worker influence on voluntary OHS management systems - A review of its ends and means. Safety Science 49(7):974-987

Frick, K. and Zwetsloot, G. (2007), From safety management to corporate citizenship: an overview of approaches to managing health", in U. Johansson, G. Ahonen and R. Roslender (eds.) Work health and management control, Stockholm: Thomson Fakta, 2007, 99-134.

Gallagher C., Underhill E., Rimmer M. (2000) Review of the effectiveness of OHS management systems in securing healthy and safe workplaces. Report prepared for the National Occupational Health and Safety Commission, Australia. Victoria University. Sept 2000 
Guastello, S.J. (1991) Some further evaluations of the International Safety Rating System Safety Science 14: 253-259

Guastello, S.J. (1993) Do we really know how well our occupational accident prevention programs work? Safety Science 16: 445-463

Hedlund FH (2000) Participation or rule - Which approach could have the better short term prospects of improving the working environment in South Africa? In: Fostervold and Enderud (eds.) Proceedings of the Nordiska Ergonomisällskapets arskonferense (NES 2000). pp. 153-156

Hedlund FH (2002) Incorporation of occupational health and safety in cleaner production projects in South Africa. PhD thesis. Ålborg University 2002

Hedlund FH (2011) Cleaner Production and Workplace Health and Safety: A Combined Approach. A Case Study from South Africa. Lambert ISBN-13:9783843394949

Hedlund FH (2013) Fatal and permanently disabling injuries in South African manufacturing industry 1970-2010 - overview, analysis and reflection. Safety Science. doi 10.1016/j.ssci.2013.01.005

Hill L (2005) NOSA International liquidated. Engineering News, Creamer's Media (South Africa), Published: 13 May 05

Labaton S (2008) S.E.C. Concedes Oversight Flaws Fueled Collapse. New York Times. September 26, 2008

Leger J.-P. (1992) "Talking rocks" - an investigation of the Pit Sense of rockfall accidents amongst underground gold miners. University of the Witwatersrand, Johannesburg, South Africa ( $\mathrm{PhD}$ thesis)

Leger, J.-P. and Macun, I.A. (1990) Safety in South African industry: An analysis of accident statistics Journal of Occupational Accidents 11:197-220

Leon, R.N.; Salamon, M.D.G.; Davies, A.W; and Davies, J.C.A (1995) Commission of inquiry into safety and health in the mining industry (Leon Commission). Government Printer vol 1-2 (Johannesburg, South Africa)

Lewis, P. (1994) Going for the stars ..... or crashing to the ground. What should the trade union movement do about NOSA. The Industrial Democracy Review 3(3):15-25

Morice, J. (1995) Safety is not just about reaching for the stars Martin Creamer's Engineering News (South Africa) 15(13):31

Nichols, T, Tucker E (2000) OHS management systems in the United Kingdom and Ontario, Canada: A political economy perspective. In: Frick, Jensen, Quinlan, Wilthagen (eds.) Systematic occupational health and safety 
management. Perspectives on an international development (2000) pp.285-309 Pergamon Press

NOSA (1997) The NOSA 5 star system. Audit workbook. Rev CMB 150 2nd ed, March 1998. National Occupational and Safety Organisation, Pretoria, South Africa

Robens, Lord (1972) Safety and health at work. Report of the committee 19701972 Her Majesty's stationary office, London

Robson LS, Bigelow PL (2010) Measurement Properties of Occupational Health and Safety Management Audits: A Systematic Literature Search and Traditional Literature Synthesis. Canadian Journal of Public Health 101(7):S34-S40

Robson LS, Clarke JA, Cullen K, Bielecky A, Severin C, Bigelow PL, Irvin E, Culyer A, Mahood Q (2007) The effectiveness of occupational health and safety management system interventions: A systematic review. Safety Science 45(3):29-353

Salminen, S.; Saari, J.; Saarela, K.L.; and Räsänen, T. (1992) Fatal and nonfatal occupational accidents: Identical versus differential causation Safety Science 15: 109-118

Shannon, H.S.; Robson, L.S.; and Guastello, S.J. (1999) Methodological criteria for evaluating occupational safety intervention research Safety Science 31: 161-179

Wagner, H. (1988) Discussion: Safety in South African mines Journal of the South African Institute of Mining and Metallurgy 88(7):233-239

Walsh D, Greenhouse S (2012) Certified Safe, a Factory in Karachi Still Quickly Burned. New York Times. December 7, 2012

Walt D (1999) NOSA goes it alone. Finance Week (South Africa). 3 Sep 1999:28 